\title{
Two contrasting patterns of crop seasonal adaptation revealed by a common garden experiment on flood recession sorghum in the Sahel
}

\author{
FOKOU YEMATA Oberline ${ }^{1,2,3,4}$, SAÏDOU Abdoul-Aziz ${ }^{1,2,6}$, KANMEGNE Gabriel $^{4}$, BERKOULA Orphé ${ }^{3,5}$, \\ AUDEBERT Alain ${ }^{1,2,3}$, SINE Bassirou ${ }^{3}$, FONCEKA Daniel ${ }^{1,2,3}$, JOLY Hélène $\mathbf{I}^{1,2}$
}

${ }^{1}$ CIRAD, UMR AGAP, F-34398 Montpellier, France

${ }^{2}$ AGAP, Univ Montpellier, CIRAD, INRA, Montpellier SupAgro, Montpellier, France

${ }^{3}$ Centre d'Etudes Régional pour l'Amélioration de l'Adaptation à la Sécheresse (CERAAS); Institut Sénégalais de Recherche Agronomique (ISRA), BP 3320, Route de Khombole, Thiès; Senegal

${ }^{4}$ Département de Biologie Végétale, Faculté des Sciences, Université de Dschang, BP 67 Dschang, Cameroon ${ }^{5}$ Département de Biologie végétale, Faculté des Sciences et Techniques, Université Cheikh Anta Diop de Dakar Senegal

${ }^{6}$ Former address: Unité Mixte de Recherche “Diversité et Adaptation des Plantes", Faculté des Sciences et Techniques, Département de Biologie, Université Dan Dicko Dankoulodo de Maradi; BP 465, Maradi Niger

\section{*Corresponding author: abdoul-aziz.saïdou@cirad.fr}

\section{Abstract}

Studying seasonal adaptation is of great importance for understanding crop diversification. The biological process of seasonal adaptation of sorghum (Sorghum bicolor (L.) Moench.) allowed the development of flood recession agrosystems in the Sahel (West and Central Africa). To analyze the patterns of trait variation linked to this poorly documented process, we evaluated and compared four eco-seasonal groups of sorghum originating from seasonally diversified agrosystems in the same cropping conditions. The muskuwaari and samme groups are composed of landraces adapted to flood recession agrosystems in the Lake Chad Basin (43 accessions) and the Senegal River Valley (14 accessions), respectively. The other two groups are composed of varieties commonly grown in the rainy season (19 accessions from the Lake Chad Basin and 24 accessions from the Senegal River Valley and and surrounding regions). Multivariate analyses based on ten agro-morphological traits structured the sample in two main clusters subdivided into four subclusters. This structure was significantly associated with the eco-seasonal groups, highlighting muskuwaari differentiation. Five traits (head appearance, leaf length, leaf number, aboveground biomass, and the root mass to aboveground biomass ratio) supported the differentiation of eco- seasonal groups and backed the hypothesis of seasonal adaptive divergence of sorghum in the Lake Chad Basin. No trait differentiation was detected in the samme group, suggesting that seasonal adaptation in the Senegal River Valley might probably be associated with population plasticity existing in the rainy season groups. These experimental evidences provide new insights for understanding scenarios of seasonal adaptation of sorghum.

Keywords: dry season sorghum; population adaptive divergence; population plasticity seasonal diversification; transplanted sorghum; Lake Chad Basin; Senegal River Valley; muskuwaari, samme.

\section{Introduction}

Studying seasonal adaptation is of great importance for understanding crop diversification (Fjellheim et al., 2014). Sorghum (Sorghum bicolor L. Moench) is one of the most drought-tolerant crop species, adapted to semi-arid environments (Borrell et al., 2006). It is an annual grass and an important staple crop in sub-Saharan Africa and South Asia, but it is also grown in various zones of the world with a dry climate, including parts of the USA and Europe. In the Sahel, sorghum is mainly grown in the rainy season (roughly from May to October). The crop displays a wide diversity of landraces belonging to different races and structured in different genetic groups (Deu et al., 2006; Billot et al., 2013). Rainy season cropping systems are dominant worldwide. They are based on clay-loam or sandy clay soils generally located in regions where rainfall is between 400 and 1000 $\mathrm{mm}$ (Chantereau et al., 2013). However, some sorghum landraces are grown during the dry season in Sahelian flood recession cropping systems in West and Central Africa. These cultivation areas include the Lake Chad Basin (northern Cameroon, Chad and northeastern Nigeria; Raimond, 1999), the Senegal River Valley (Senegal, Mauritania; Le Roy, 2005) and northern Mali (Harlan and Pasquereau, 1969). Sowing takes place in the middle or at the end of the rainy season, followed by growing and reproductive cycles in the dry season (Bruckmann, 2016). Clayey flooded soils, particularly vertisols, are the main types of soils for these farming practices, which are established in floodplains, wetlands, inland valleys and on lake shores (Sidibé et al., 2016). In India, post-rainy sorghum varieties (rabi) are sown between September and October and grown under receding soil moisture conditions, without irrigation (Patil et al., 2014). 
Most dry season sorghum landraces are classified in the durra race and, rarely, in caudatum or kafir (Stemler et al., 1975; Soler et al., 2013; Raimond 1999; Patil et al., 2014; Zach et al., 1996; Naoura et al., 2019). The origin of these landraces is not well known. Studies in the Lake Chad Basin analyzed their genetic relationship with landraces grown in the rainy season (Soler, 2012; Saïdou et al., 2014).

Dry season sorghum landraces of the Lake Chad Basin have complex local taxonomies (Saïdou et al., 2014). The main types are called muskuwaari (northern Cameroon), masakwa (northeastern Nigeria), or berbere (southern Chad) (Raimond, 1999). Seeds are sown in the middle of the rainy season (from mid-August) in small nurseries (sandy soils) close to the village or the field. Seedlings are transplanted to vertisol fields (called karal in northern Cameroon) following flood recession (between October and November). Sowing in the nursery is commonly replicated by farmers two to four times, in order to match a transplanting stage (seedlings of around $40-45$ days and 30 to $40 \mathrm{~cm}$ tall) to the variable flood recession time. Harvesting is carried out from February to March (Barrault et al., 1972; Carsky et al., 1995).

Unlike in the Lake Chad Basin, flood recession sorghum landraces in the Senegal River Valley (samme) are sown directly in the field in flood plains (kolangal) following the recession flow at the end of the rainy season, from October to November (Le Roy, 2005; Bruckmann, 2016). The harvesting period is from March to April (Chantereau, 2002). The adaptation of annual grasses to dry season involves the ability of the plant to respond to a shift in environmental conditions (Fjellheim et al., 2014). For sorghum, this includes adaptation to a water regime based on the water stock remaining in the soil (mainly vertisols), a response to the temperature and photoperiod changes and to specific farmers management practices (particularly in the Lake Chad Basin, where sowing in a nursery and transplanting practices are widespread).

Knowledge about plant adaptation to variations in water regimes and temperatures (including drought) could help to identify some of the adaptive traits linked to seasonal adaptation (Redmann, 1985). Various combinations of morpho-physiological features contribute to the ability of plants to adapt to these variations, including shorter plants, smaller leaf area, increased root biomass and high chlorophyll content; all of which are beneficial under drought stress in order to avoid desiccation (Jaleel et al., 2008; Richards et al, 2010). Some plants modify the root to shoot dry matter ratio (in favor of the former) in response to drought (Passioura, 2012). The survival of deep-rooted seedlings after drought is greater than that of shallowrooted seedlings (Padilla and Pugnaire, 2007). In wheat genotypes, a cultivar resistant to water stress was found to have a high chlorophyll content (Sairam et al., 1997). Plant resistance to drought also relies on adaptive strategies based on the timing of phenophases. Early flowering or fruiting capacity have also been found to be associated with drought escape under rainfed conditions (De Micco and Aronne, 2012; Franks et al., 2007).

Agro-morphological and phenological variations in dry season sorghum in the Lake Chad Basin have been described notably in flood recession cropping systems (Barrault et al., 1972; Kenga and Djorowe, 2008; Naoura et al., 2019). Izge and Alimta (2008) compared the performance of one dry season sorghum (masakwa) and six rainy season sorghums under rainfed conditions in Nigeria. A preliminary study by our laboratory compared 10 rainy season sorghum varieties to around 150 dry season landraces under dry season cropping conditions and suggested genetic differentiation of genotypes for flowering times and morphological traits (Ekeke, 2012).

To our knowledge, no study has addressed the basis of seasonal adaptation of sorghum in flood recession systems. The patterns underlying the crop adaptation to dry season cropping in the Lake Chad Basin (muskuwaari) and in Senegal River Valley (samme) are also unknown.

In the current study, we designed a common garden experiment in the rainy season in Senegal (Bambey station, ISRA) to study the phenotypic variation of four eco-seasonal sorghum groups including dry season sorghum and rainy season sorghum from both the Lake Chad Basin and the Senegal River Valley. We used a set of agro-physiological traits related to phenology, leaf physiology, root growth and biomass to assess the phenotypic structure and its link with factors shaping seasonal diversification. This study highlighted two contrasting patterns underlying seasonal adaptation in muskuwaari and samme sorghum, respectively. The first is highly differentiated from rainy season sorghum, and showed evidence for an adaptive divergence; the second showed evidence of population plasticity.

Results

This study used a common garden experiment in the rainy season at Bambey (Senegal) to assess the pattern of seasonal adaptation of sorghum based on the analysis of agro-physiological variation of four eco-seasonal groups represented by 100 accessions ( $25 \pm 6.34$ accessions on average per eco-seasonal group).

\section{Agro-physiological structure of the sample}

Principal component analysis (PCA) grouped in a separate side muskuwaari accessions (characterized by a late heading and shorter leaves), while accessions from all the other groups were mixed (Figure 1). The structure revealed by PCA appeared to be supported by heading date and leaf length. This structure was refined using DAPC (Figure 2). In this analysis, we compared two criteria (BIC and DiffNgroup) to infer the number of clusters (Figure S2a and Figure S2b). DiffNgroup was more consistent and confirmed the number of two main clusters structuring the sample (Figure S2b). The two clusters had balanced sizes (Table 3$)$. Cluster $1(n=50)$ consisted mainly of dry season sorghum accessions from Lake Chad Basin (muskuwaari, $\mathrm{n}=41$ ) with a few rainy season accessions from Lake Chad Basin $(n=5)$ and Senegal River Valley $(n=4)$. Cluster $2(n=49)$ was a mixture of accessions belonging to the other eco-seasonal groups, apart from muskuwaari.

Using $K=4$, we obtained a consistent split of the 2 previously described clusters, each into two subgroups (Figure 2; Table 3). Cluster 1a was almost exclusively composed of muskuwaari (Table 3$)$. Cluster $1 \mathrm{~b}(\mathrm{n}=21)$ was also composed of muskuwaari (two-thirds) but included a mixture of the other eco-seasonal groups (one third). Cluster 2a $(n=26)$ and Cluster $2 b(n=26)$ included accessions from all eco-seasonal groups except muskuwaari (only two and one muskuwaari accessions were assigned to these subclusters, respectively). Factors associated with agro-physiological structure

We found a significant association between the inferred structure and, respectively, the eco-seasonal group, the seasonal type, the geographical origin and the race (Chisquared test; $\mathrm{P}<10^{-05} ;$ Table 4). Accounting for potential bias 
of uncertainty in accession assignation over DAPC using the described ad hoc procedure, we discarded artefact effects of marginal accessions in each cluster and validated these tests (Table S5). Of all the factors, the eco-seasonal group had the highest level of association $\left(P=1.85 \times 10^{-14}\right.$ and $P=1.16 \times 10^{-}$ ${ }^{10}$ at $\mathrm{K}=2$ and $\mathrm{K}=4$, respectively; Table 4 ), suggesting a major structuring effect of the eco-seasonal diversification on the variation in agro-physiological traits of sorghum. Muskuwaari accessions were all from the durra race (Table S4; Table S1). The racial differentiation between clusters clusters was supported by the predominance of the durra race in Cluster 1 (Table S4).

\section{Variation in agro-physiological traits between eco-seasonal groups and between inferred clusters}

The summary statistics of the traits according to the four eco-seasonal groups were computed (Table S2). Two of the traits exhibited a statistically significant distribution shift between eco-seasonal groups for head appearance $(P=3.08$ $\left.\times 10^{-11}\right)$ and leaf length $\left(P=1.51 \times 10^{-03}\right.$ ) (Table S6a; Figure 3). Pairwise comparisons suggested that the muskuwaari group was differentiated form the other types (Tukey test, Table S6b). Muskuwaari flowered significantly later (115 days, on average, from sowing to head appearance), compared to the other three groups (average values grouped between 74 and 81 days). This eco-seasonal group also exhibited shorter leaves (LL average of $50.36 \mathrm{~cm}$ versus 68.15 for samme, $68.72 \mathrm{~cm}$ for rainy season varieties of the Lake Chad Basin, and $72.77 \mathrm{~cm}$ for rainy season varieties of the Senegal River Valley).

The evaluated traits statistics were also computed according to the inferred clusters (Table S3). The analysis of variance of the traits according to the inferred clusters $(K=2)$ showed a significant distribution shift between Cluster 1 (mainly composed of muskuwaari) and Cluster 2 for head appearance, leaf length, leaf number, aboveground biomass and the root mass to aboveground biomass ratio (Figure 4; Table S7a).

We also deciphered the differentiations between the four subclusters (Table S7b). The subclusters $1 \mathrm{a}$ and $1 \mathrm{~b}$ containing muskuwaari were differentiated from each other based on leaf width $\left(P=5.80 \times 10^{-06}\right)$, root number $(P=1.00 \times$ $\left.10^{-06}\right)$, and aboveground biomass $\left(P=9.04 \times 10^{-06}\right)$. The Cluster 1a (exclusively composed of muskuwaari) had a larger leaf width (average difference of $+1.53 \mathrm{~cm}$ ), more aboveground biomass (+123.39 g per plant), and a smaller root number (-23.69 roots per plant), compared to the Cluster 1b (Figure S3).

Across the two eco-geographical zones, three traits were significantly shaped by the seasonal type of sorghum, namely head appearance, leaf length and aboveground biomass (Table S6a). Four traits varied between ecogeographical across all accessions (Table S6a).

\section{Discussion}

\section{Signal of eco-seasonal structure in sorghum validated with} robust statistical procedures

We used an ad hoc validation procedure to overcome statistical shortcomings in DAPC structure inference, notably the uncertainty in the inference of the number of clusters and in the assignation of accessions to the inferred clusters (Jombart et al., 2010; Soler et al., 2013).
Using empirical in silico resampling on our data, we showed that BIC is sensitive to sample size and provides unstable results across runs (Figure S2a). This criterion tended to detect a larger number of clusters (fine level of structure). The DiffNgroup criterion (derived from BIC) detected a basic level of structure (small number of clusters), which was consistent across resampled data and less sensitive to sample size (Figure S2a). We therefore opted for the number of clusters suggested by this criterion $(\mathrm{K}=2)$. This was also consistent with the PCA projection (Figure 1). All DAPC runs were performed without including a priori eco-seasonal group information. So the assignation of all muskuwaari accessions in the same cluster by DAPC a posteriori indicated an actual phenotypic differentiation (Table 3).

The statistical association of seasonal type, eco-geographical origin, eco-seasonal group, race and country of origin with the phenotypic structure was consistent regardless to the uncertainty in the assignation of marginal accessions in the clusters (Table 4; Table S5).

Identification of the agro-physiological traits and mechanisms linked to seasonal adaptation

The reason for using a common garden experiment was to make environmental and cropping conditions similar, in order to enable the analysis of genetic differences between the four studied populations (Vitasse et al., 2009). Each group was represented by an average of $25 \pm 6.33$ accessions (the minimum being $n=14$; Table 1 ) representing the diversity of the group.

Over all presented analyses, we identified five traits that differentiated the muskuwaari type (or clusters predominantly composed of muskuwaari) from the other eco-seasonal groups, namely head appearance, leaf length, leaf number, aboveground biomass and the root mass to aboveground biomass ratio. Muskuwaari landraces are very late flowering when sown in the rainy season. During this trial, the muskuwaari landraces sown in July flowered between December and January (around 6 to 7 months' duration). This behavior has been described in northern Cameroon (Barrault et al., 1972). It was linked to the high photoperiod sensitivity of muskuwaari (Chantereau et al., 2013; Craufurd et al., 1999).

Leaf size reduction is a mechanism for adjusting leaf area to avoid stress (Blum and Sullivan, 1986). Larger values of the root mass to aboveground biomass ratio indicate an increase in root density over leaf area, a phenomenon that offers the advantages of minimizing water loss and maximizing water uptake in a context of water stress (Passioura, 2012). Under the conditions of our trial (no induced water stress), the dry season accessions (particularly muskuwaari from Cluster 1) showed a lower root mass to aboveground biomass ratio, compared to the rainy season accessions. This could indicate more efficient water uptake and use, meaning an ability to produce more aboveground biomass with fewer roots.

Leaf area reduction is one of the mechanisms involved in limiting evapotranspiration (Levitt, 1972). Although this trait did not show a significant difference between the four ecoseasonal groups (Table S6a), it was found that the mean of leaf area of dry season sorghum tended to be lower than that of the rainy season sorghums, particularly for the accessions from the Senegal River Valley (Table S2). Variation in leaf width is associated with drought adaptation in grasses (Redmann 1985). 
Table 1. Presentation of the sampled sorghum panel ( $n=100$ accessions)

\begin{tabular}{|c|c|c|c|c|c|c|c|}
\hline & \multicolumn{3}{|c|}{ Lake Chad Basin (LCB) } & \multicolumn{3}{|c|}{ Senegal River Valley (SRV) } & \multirow[b]{2}{*}{ Total } \\
\hline & Cameroon & Chad & Total & Mauritania & Senegal & Total & \\
\hline Rainy season sorghum (RSS) & 19 & 0 & 19 & 0 & 24 & 24 & 43 \\
\hline Dry season sorghum (DSS) & 32 & 11 & 43 & 2 & 12 & 14 & 57 \\
\hline Total number of accessions & 51 & 11 & & 2 & 36 & & 100 \\
\hline
\end{tabular}

The number of accessions sampled is presented according to the eco-geographical origin of the accessions (LCB or SRV) and their seasonal type (RSS or DSS). The cross between an eco-geographical origin and a seasonal type defined an eco-seasonal group. In the text, LCB DSS will be refered to as muskuwaari and SRV DSS will be refered to as samme.
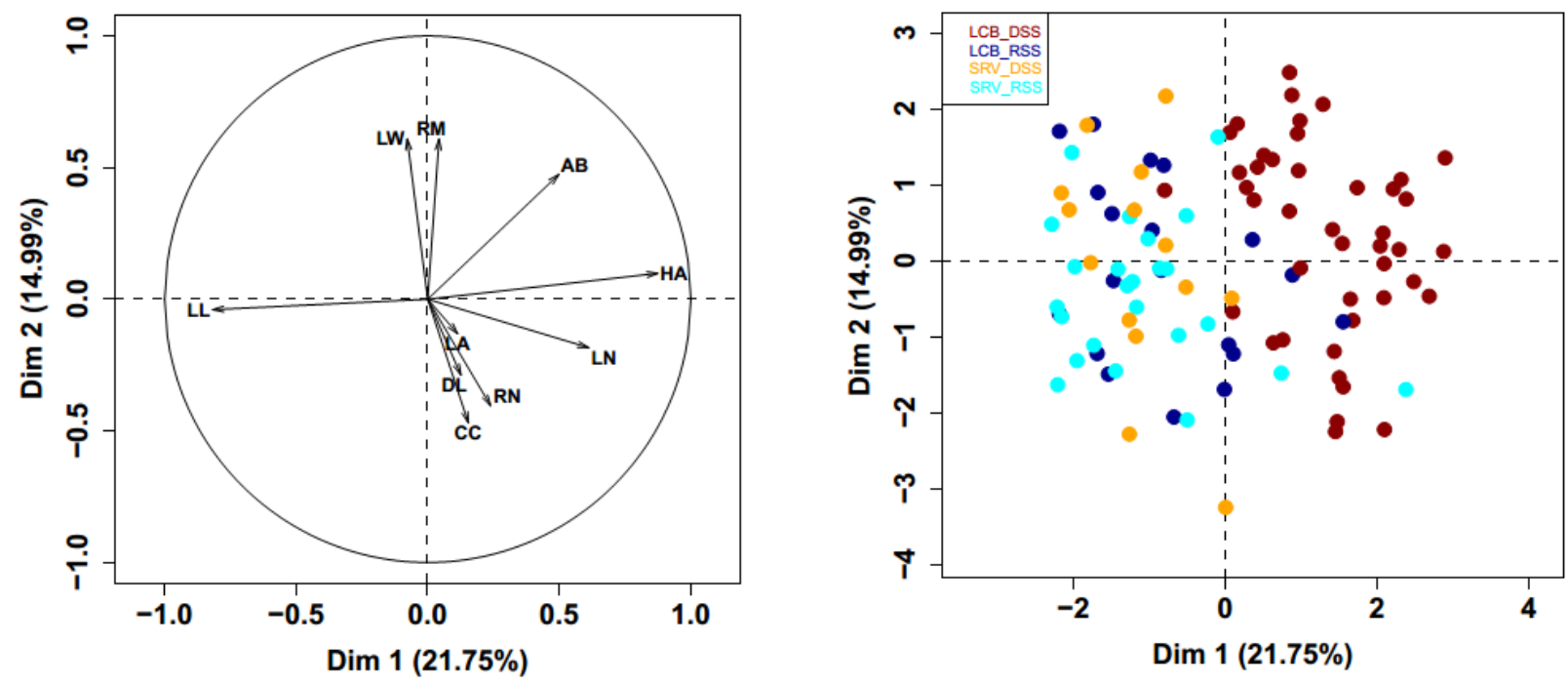

Fig 1. Projection of the traits and the accessions by principal component analysis (PCA). A. Correlation circle of the 10 considered traits. B. Projection of the 100 accessions, colored according to the eco-seasonal group. Dry season sorghum from Lake Chad basin (left; in red) appeared as the most distinguished group. HA : head appearance, LW : leaf width, LL : leaf length, LN : leaf number, DL : leaf dead percentage, CC : chlorophyll content, LA : leaf area, RN : root number, RM : root dry weight, AB : aboveground biomass.

Table 2. List and definition of the agro-physiological traits.

\begin{tabular}{|c|c|c|c|c|}
\hline Characters & Code & Category & Measurement method & Unit \\
\hline $\begin{array}{l}\text { 1. Head } \\
\text { appearance }\end{array}$ & $\mathrm{HA}$ & Phenology & Number of days from sowing to heading & day \\
\hline 2. Leaf width & LW & Leaf trait & Width of the third leaf below the last ligulated leaf & $\mathrm{cm}$ \\
\hline 3. Leaf length & $\mathrm{LL}$ & Leaf trait & Length of the third leaf below the last ligulated leaf & $\mathrm{cm}$ \\
\hline 4. Leaf number & $\mathrm{LN}$ & Leaf trait & $\begin{array}{l}\text { Count of the number of harvested leaves (including green, dead } \\
\text { and fallen leaves) }\end{array}$ & - \\
\hline $\begin{array}{l}\text { 5. Percentage of } \\
\text { dead leaves }\end{array}$ & $\mathrm{DL}$ & Leaf trait & $\begin{array}{l}\text { Number of dead leaves at harvest divided by total number of } \\
\text { observed leaves at harvest }\end{array}$ & $\%$ \\
\hline $\begin{array}{l}\text { 6. Chlorophyll } \\
\text { content }\end{array}$ & $\mathrm{CC}$ & Leaf trait & $\begin{array}{l}\text { Chlorophyll content in leaf green tissue obtained with SPAD (three } \\
\text { measurements per leaf, early in the morning) }\end{array}$ & - \\
\hline 7. Leaf area & LA & Leaf trait & $\begin{array}{l}\text { Area of all the green leaves of the plant before harvest calculated } \\
\text { using the formula of Stickler et al., (1961) (length } x \text { width } \times 0.747 \text { ) }\end{array}$ & $\mathrm{cm}^{2}$ \\
\hline 8. Root number & $\mathrm{RN}$ & Root trait & Count of the number of nodal roots. & - \\
\hline 9. Root mass & RM & Root trait & $\begin{array}{l}\text { Roots from each individual plant collected and dried separately at } \\
60^{\circ} \mathrm{C} \text { for } 72 \text { hours before obtaining dry mass. }\end{array}$ & g \\
\hline $\begin{array}{l}\text { 10. Aboveground } \\
\text { biomass }\end{array}$ & $A B$ & Biomass & $\begin{array}{l}\text { Leaves and stems collected from each individual plant and dried } \\
\text { separately at } 60^{\circ} \mathrm{C} \text { for } 72 \text { hours before obtaining dry mass. }\end{array}$ & g \\
\hline
\end{tabular}


a) $\mathrm{K}=\mathbf{2}$

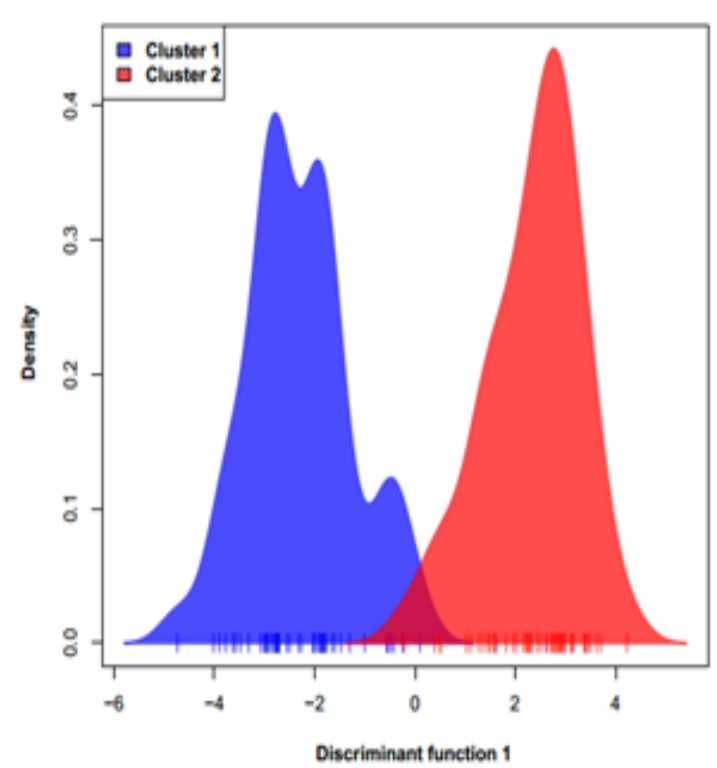

b) $\mathrm{K}=4$

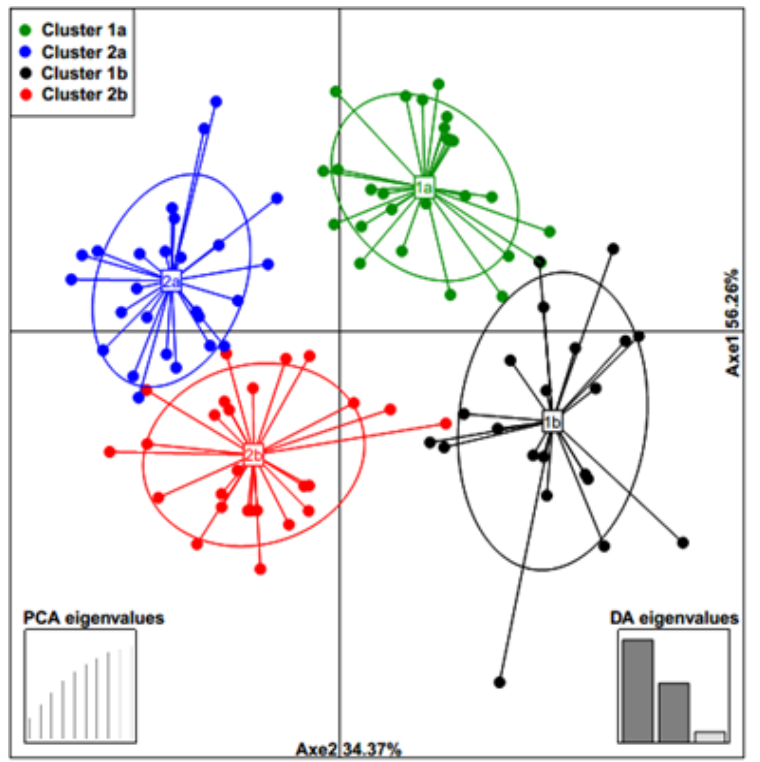

Fig 2. Structure of sorghum panel revealed by discriminant analysis of principal components (DAPC). a) $K=2$. The two clusters (Cluster 1 and Cluster 2) are represented and distinguished with color codes. b) $K=4$. Cluster 1 (identified in subplot a) was split into two subclusters: $1 a$ and $1 b$; Cluster 2 was split into $2 a$ and $2 b$. Clusters are shown by different colors and inertia ellipses, while dots represent individual accessions. The first two discriminant functions are plotted, explaining a total of 93.63\% of the variance.

Table 3. Repartition of the number of accessions between clusters inferred using DAPC and eco-seasonal groups. a. Contingency table between clusters inferred using DAPC and the eco-seasonal groups.

\begin{tabular}{|c|c|c|c|c|c|c|}
\hline \multirow[b]{2}{*}{ Eco-seasonal groups } & \multicolumn{2}{|c|}{ Clusters ( $\mathrm{K}=2)$} & \multicolumn{4}{|c|}{ Subclusters $(\mathrm{K}=4)$} \\
\hline & 1 & 2 & $1 a$ & $1 b$ & $2 a$ & $2 b$ \\
\hline LCB DSS & 41 & 1 & 25 & 14 & 2 & 1 \\
\hline LCB RSS & 5 & 14 & 1 & 3 & 7 & 8 \\
\hline SRV DSS & & 14 & & 1 & 7 & 6 \\
\hline SRV RSS & 4 & 20 & & 3 & 10 & 11 \\
\hline Cluster size & 50 & 49 & 26 & 21 & 26 & 26 \\
\hline
\end{tabular}

b. Contingency table between the two main clusters $(K=2)$ and the four subclusters $(K=4)$.

\begin{tabular}{llllll}
\hline \multirow{2}{*}{ Clusters } & & $\mathrm{K}=4$ & & \\
\cline { 2 - 5 } & & $1 \mathrm{a}$ & $1 \mathrm{~b}$ & $2 \mathrm{a}$ & $2 \mathrm{~b}$ \\
\hline $\mathrm{K}=2$ & 1 & 26 & 20 & 2 & 2 \\
& 2 & & 1 & 24 & 24 \\
\hline
\end{tabular}

a) Repartition of the number of accessions from inferred clusters in the eco-seasonal groups of accession origin. b) Repartition of the number of accessions from the two main inferred clusters ( $\mathrm{K}=2$ ) in the four inferred clusters (K=4). LCB: Lake Chad Basin, SRV: Senegal River Valley, DSS: dry season sorghum, RSS: rainy season sorghum.
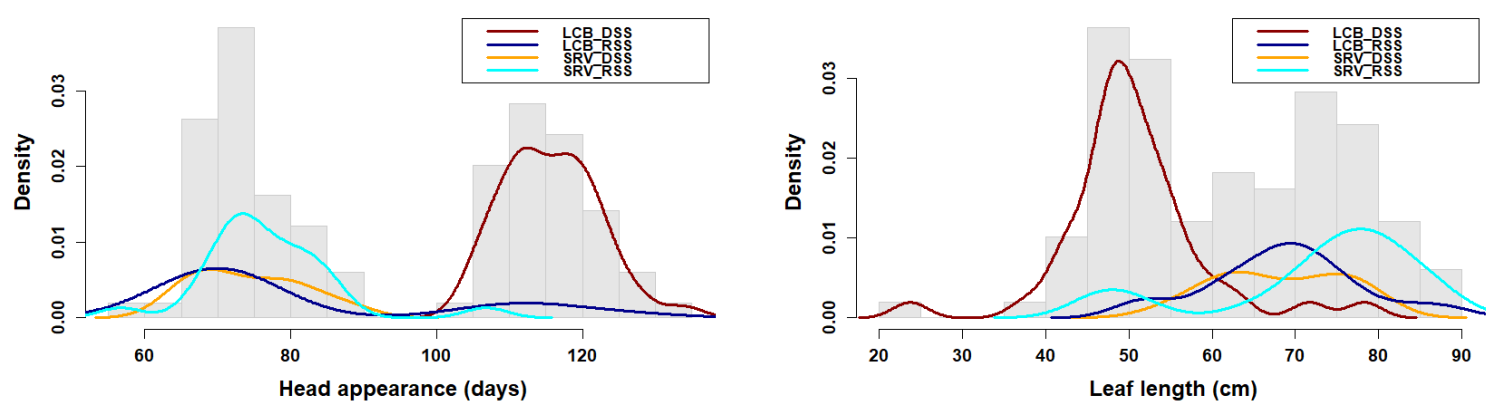

Fig 3. Distribution of head appearance and leaf length according to sorghum eco-seasonal group. Muskuwaari group (LCB_DSS) showed a distribution shift, suggesting phenotypic differentiation from rainy season sorghum (later flowering and shorter leaves). Samme group (SRV_DSS) distribution did not differentiate from that of the two rainy season groups. 
Table 4. P-values of association between the classification factors and the inferred clusters (Chi-squared test).

\begin{tabular}{lcccc}
\hline $\begin{array}{l}\text { Inferred } \\
\text { clusters (DAPC) }\end{array}$ & $\begin{array}{c}\text { Eco-geographical zone of } \\
\text { origin }(\mathrm{n}=2)\end{array}$ & $\begin{array}{c}\text { Seasonal type }(\mathrm{n}=2) \\
\mathrm{K}=2\end{array}$ & $\begin{array}{c}\text { Eco-seasonal group } \\
(\mathrm{n}=4)\end{array}$ & $\begin{array}{c}\text { Race ( }=8) \\
(\mathrm{n}=4)\end{array}$ \\
$\mathrm{K}=4$ & $9.26 \times 10^{-09}$ & $7.25 \times 10^{-07}$ & $1.85 \times 10^{-14}$ & $1.32 \times 10^{-08}$ \\
\hline
\end{tabular}
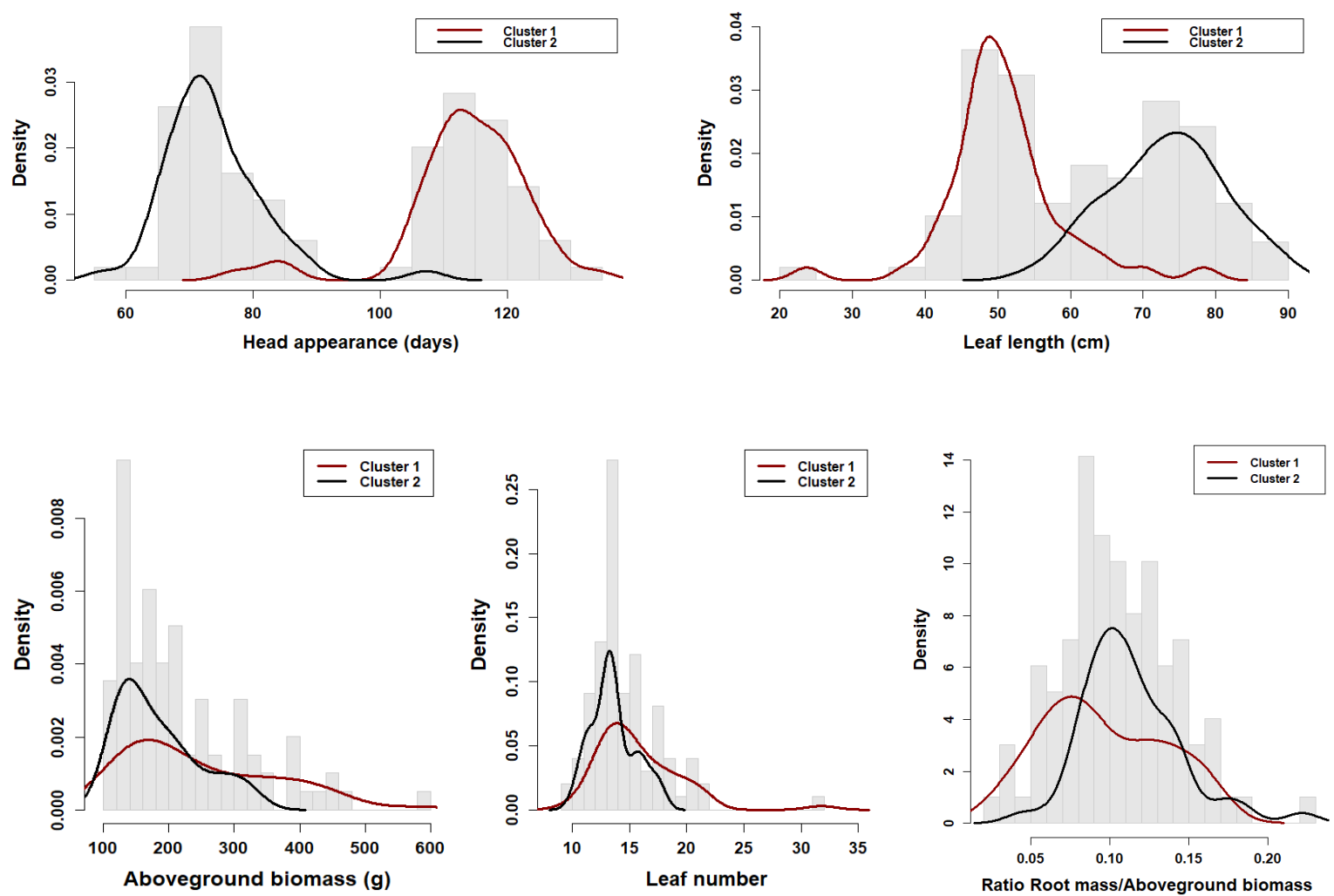

Fig 4. Distribution of five traits differentiating Cluster 1 from Cluster 2. Trait distribution based on the BLUPs is shown according to the two main clusters inferred by DAPC.

These results provided candidate traits and candidate mechanisms for understanding the seasonal adaptation of sorghum. Further physiological studies are needed to validate the mechanisms underlying these features. Genome-wide association studies (GWAS) could assess the link between these traits and the polymorphisms associated with seasonal adaptation (Fjellheim et al., 2014).

Dry season in the Lake Chad Basin and the Senegal River Valley: contrasting patterns of seasonal adaptation?

The differentiations shown in five traits suggested that seasonal adaptation of sorghum in the Lake Chad Basin might be linked to population adaptive divergence of muskuwaari. This backed the hypothesis of an adaptive evolution that genetically shaped the evolutionary history of muskuwaari (Saïdou et al., 2014).

Dry season sorghums from the Senegal River Valley (samme) included diverse races (D, DC, G, GC) and exhibited an agronomic behavior close to that of the rainy season sorghum varieties. This eco-seasonal group did not show any significant trait differences with the rainfed accessions. This suggested that the adaptation of sorghum to dry season cultivation in flood recession systems of the Senegal River Valley might be based on the expression of a population phenotypic plasticity existing in rainy season sorghum.

\section{Material and methods}

\section{Studied sorghum panel}

The studied sorghum panel is composed of four ecoseasonal groups of landraces: muskuwaari (landraces grown in dry season sorghum in Lake Chad Basin, generally transplanted), samme (landraces grown in dry season in Senegal River Valley), rainy season landraces from the Lake Chad Basin and rainy season landraces from the Senegal River Valley and surrounding regions (Table 1). These groups were represented by respective samples of $43,14,19,24$ accessions, corresponding to a panel of 100 accessions (see Table S1 for passport data and Figure S1 for the map of locations of origin of the accessions). This panel is part of a larger Sorghum Seasonal Study Panel (S3P; $n=153$ accessions) evaluated at Bambey (Senegal).

\section{Field trial}

The four eco-seasonal groups were evaluated in a common garden experiment carried out during the rainy season 2016 at the Centre National de Recherche Agronomique of Bambey, ISRA (Senegal). The accessions representing each of the four eco-seasonal groups were randomly assigned to the plots using a design with spatial control of plots heterogeneity. The spatial control was allowed by the mapping of plot position in the field (row and column 
coordinates recorded) to capture the heterogeneity among plots. Seeds were sown on the $28^{\text {th }}$ July 2016 under natural rainfed conditions ( 5 seeds per hill). A thinning was done 15 days after sowing to keep only two seedlings per hill. All plots received supplemental irrigation at the end of the rainy season to allow for the completion of the cycle of late flowering varieties (last harvest on January the $3^{\text {rd }}$ 2017). Each plot measured $3.2 \mathrm{~m} \times 3.2 \mathrm{~m}$ and spaced $1 \mathrm{~m}$ from the others. Inside plots, $0.8 \mathrm{~m}$ spacing between hills was used in each side. For each accession, 25 hills were sown (one plot per accession). Four plants per accession (from four different hills) were used for the traits measurements and notations.

\section{Phenotypic traits notation}

Ten traits related to phenology, leaf, root, and plant biomass were measured (Table 2). Two other traits were calculated from the measured traits: the ratio RM/LA (root mass over leaf area) and the ratio RM/AB (root mass over aboveground biomass). Except for the date of heading and leaf chlorophyll content, all traits were measured at harvest period. Leaf chlorophyll content was evaluated before harvest, based on SPAD chlorophyll meter (Süß et al., 2015).

Phenotypic data modelling and accession BLUP extraction

The recorded data were analyzed independently for each trait using a linear mixed-effects model accounting for the spatial structure of the design to estimate accession effect while controlling for field heterogeneity. The linear mixed model was set as follows:

$Y=\mu+S \alpha+X \beta+e($ model 1$)$

$Y$ is the vector of phenotype, $\mu$ is the intercept, $\alpha$ is the vector of the random effects of the plot spatial position in the field, $\beta$ is the vector of the random effects of the accession and e is the vector of residual effects. $S$ is the twodimensional array of plot coordinates into the plan of the field (row, column); $X$ is the occurrence matrix of accessions. The term $\alpha$ was fitted using five alternative models of spatial covariance: gaussian, exponential, linear, quadratic and spherical. The model with the best fit based on Akaike Information Criterion, AIC (Crawley, 2007) was then retained.

Best linear unbiased predictors (BLUP) were extracted from the fitted model as:

$Y^{\prime}=\mu+X \beta$ (model $\left.1 \mathrm{a}\right)$.

The model was fitted using the package nlme (version 3.1-

137) in R (version 3.4.3; R Core Team, 2017).

Inference of population agro-physiological structure

Discriminant analysis of principal components (DAPC) (Jombart et al., 2010) was used to infer the structure (adegenet R package) of the sample based on the BLUPs of the 10 measured traits described above (Table 2). Two criteria proposed by Jombart et al. (BIC and DiffNgroup) were used to infer the optimal number of clusters, $\mathrm{K}$ (K varied from 1 to 20). We assessed the effect of sample size and the effect of across runs variability on the inference of the optimal number of clusters for each criteria. The procedure was defined as follows: i) randomly sample a subset of accessions of size $n$ with no replacing ( $n$ varied from 40 to 99); ii) for the sampled subset, make a run of find.clusters() function and choose the best value of $\mathrm{K}$ using $\mathrm{BIC}$ and diffNgroup independently; iii) repeat the analysis 100 times for each value of $n$; iv) compute the frequency of choice of each possible values of $\mathrm{K}$ over the 100 runs for each sample size. Next, DAPC was ran at chosen values of $K$ to make the final clustering and assign accessions into the clusters. One accession over the 100 was discarded from this analysis due to missing data (CM134). The number of principal components retained during the process of DAPC was determined with the cross-validation approach implemented in the function xvalDapc(), with 1000 repetitions. This optimization was tested by varying the number of $\mathrm{K}$ only from 2 to 10 . The number of principal components was set to eight after exploratory analysis, accounting for about $86 \%$ of the total phenotypic variance.

Test of association between inferred phenotypic structure and sampling factors

We performed Chi-square tests to assess the association of the inferred phenotypic structure with each of the factors (eco-seasonal groups, race, region of origin and seasonal type). As the assignation of accessions to DAPC clusters could be variable over runs, we validated the robustness of the association using Chi-square test replication based on accessions in silico resampling (Table S5). The resampling was structured with respect to the Euclidian distance of accessions to DAPC clusters' centre. Our assumption was that subsamples composed of individuals closer to cluster centres are the best-assigned accessions and reflect an unbiased trend of association with the factors.

Analysis of variance of the traits

For each trait, an analysis of variance was performed based on two respective models. The first model fitted the effect of eco-seasonal group and its underlying factors (seasonal type and eco-geographical of origin) as follows:

$Y_{i j k}=\mu+\alpha_{i}+\beta_{j}+\gamma_{i j}+\varepsilon_{i j k}($ model 2$) ;$

$\mathrm{Y}_{\mathrm{ijk}}$ is the $\mathrm{k}^{\text {th }}$ phenotypic value for the $\mathrm{i}^{\text {th }}$ level of factor $A$ (seasonal type, with fixed effect $\alpha_{i}$ ) and the $\mathrm{j}^{\text {th }}$ level of factor B (eco-geographical origin, with fixed effect $\beta_{j}$ ); $\mu$ is the grand mean; $\gamma_{\mathrm{ij}}$ is the effect of eco-seasonal group (which correspond to the interaction between $A$ and $B$ ) and $\varepsilon_{i \mathrm{jk}}$ is the residual.

The second model fitted the effects of inferred DAPC clusters:

$Y_{i j}=\mu+\alpha_{i}+\varepsilon_{i j}$ (model 3);

Where $Y_{i j}$ represents the phenotypic value for the $j^{\text {th }}$ observation in the $i^{\text {th }}$ cluster; $\mu$ is the intercept; $\alpha_{i}$ represents the fixed effect of the cluster $\mathrm{i}$ and $\varepsilon_{\mathrm{ij}}$ represents the random error.

For the $\mathrm{Y}$ vector in these two models, we used the BLUPs previously estimated (model 1a). All the accessions representing an eco-seasonal group were used as random repeats for this group. When the analysis of variance was significant $(\mathrm{P}<0.05)$, Tukey's honestly significant difference (HSD) was used to check pairwise differences.

\section{Conclusion}

This study showed that the agro-physiological traits diversity of sorghum supports an eco-seasonal structure linked to the diversification of the crop in Lake Chad Basin. Dry season sorghum from the Lake Chad Basin (muskuwaari), and the associated clusters (Cluster 1, Subclusters $1 \mathrm{a}$ and 1b), showed a differentiation from rainy season sorghum based on head appearance, leaf length, leaf number, aboveground biomass, and the root mass to aboveground biomass ratio. This pattern of trait shift, observed through a common garden experiment with controlled design, backs a hypothesis of genetic differentiation and adaptive divergence linked to the seasonal diversification of sorghum. The dry season sorghum group from Senegal River Valley (samme), showed no particular trait shift compared to both rainy season groups. This pattern, contrasting with the one 
observed in muskuwaari, suggested that the seasonal adaptation of samme was more likely supported by a population plasticity in the rainy season sorghum. These evidences provided new insights for understanding the seasonal adaptation of sorghum in the flood recession agrosystems and, more widely, the seasonal adaptation of annual crop species.

\section{AUTHORS' CONTRIBUTIONS}

AAS, HIJ, OF, AA and DF designed the study. OB, OF, BS and $A A$ conducted the trials. OF and AAS carried out statistical analyses. All the authors took part in discussing the results. AAS, OF, GK and HIJ wrote the paper.

\section{DECLARATIONS OF INTEREST: There is no conflict.}

\section{Acknowledgements}

The authors acknowledge the Centre d'Etude Régional pour l'Amélioration et l'Adaptation à la Sécheresse (CERAAS; Senegal) and the Institut de Recherche Agricole pour le Développement (IRAD, Cameroon; C2D/PAR - SORGHO Project) for logistic and financial support. We thank the field staff of the Centre National pour la Recherche Agronomique in Bambey for plot management and assistance with data collection, particularly Pape Ndiaye, Mamadou Ba and Diaw Fall. Many thanks to Bounama Sall for the identification of sorghum races. OF was supported by PhD grants from DAAD (Germany). She benefited from CIRAD facilities (UMR AGAP) and from SCAC (French Embassy, Cameroon) support during sandwich stays in Montpellier. We also thank Yakouba Oumarou (University of Maroua), Gabriel Djorwe (IRAD), Andre Djonnewa (IRAD) and Venasius Lendzemo (IRAD) for facilitating the choice of Lake Chad Basin accessions and sending seed material from IRAD, Maroua.

\section{References}

Barrault J, Eckebil JP, Vaille J (1972) Point des travaux de I'IRAT sur les sorghos repiqués du Nord-Cameroun. Agron Trop. 27(8): 791-814.

Billot C, Ramu P, Bouchet S, Chantereau J, Deu M, Gardes L, Noyer JL, Rami JF, Rivallan R, Li Y, Lu P, Wang T, Folkertsma RT, Arnaud E, Upadhyaya HD, Glaszmann JC, Hash CT (2013) Massive sorghum collection genotyped with SSR markers to enhance use of global genetic resources. Plos One. 8(4): e59714.

Blum A, Sullivan CY (1986) The Comparative Drought Resistance of Landraces of Sorghum and Millet From Dry and Humid Regions. Ann Bot-London. 57(6): 835-846.

Borrell A, Jordan D, Mullet J, Henzell B, Hammer G (2006) Drought Adaptation in Sorghum. In: Ribaut MJ (ed) Drought Adaptation in Cereals. Haworth Press, New York, 335-378.

Bruckmann L (2016) L'intégration des zones inondables dans la gestion de l'eau et le développement de l'irrigation d'une vallée fluviale sahélienne : le cas des terres de décrue de la moyenne vallée du Sénégal. PhD thesis, Université Paris Diderot - Paris 7, France.

Carsky RJ, Ndikawa R, Singh L, Rao MR (1995) Response of dry season sorghum to supplemental irrigation and fertilizer $\mathrm{N}$ and $\mathrm{P}$ on Vertisols in northern Cameroon. Agr Water Manage. 28(1): 1-8.

Chantereau J (2002) Connaissance et utilisation de la diversité des sorghos de décrue en Afrique de l'Ouest et du Centre au Cirad. In: Comas J, Gomez MacPherson H (ed) La Culture du
Sorgho de décrue en Afrique de l'Ouest et du Centre. $\mathrm{AECl} / \mathrm{FAO}$

Chantereau J, Cruz JF, Ratnadass A, Trouche G, Fliedel G (2013) Le sorgho. Versaille, Ed Quae.

Craufurd PQ, Mahalakshmi V, Bidinger FR, Mukuru SZ, Chantereau J, Omanga PA, Qi A, Roberts EH, Ellis RH, Summerfield RJ, Hammer GL (1999) Adaptation of sorghum: characterisation of genotypic flowering responses to temperature and photoperiod. Theor Appl Genet. 99: 900911.

Crawley M (2007) The R Book. John Wiley \& Sons, UK.

De Micco V, Aronne G (2012) Morpho-Anatomical Traits for Plant Adaptation to Drought. In: Aroca $R$ (ed) Plant Responses to Drought Stress: From Morphological to Molecular Features. Springer, Berlin Heidelberg, 37-61.

Deu M, Rattunde F, Chantereau J (2006) A global view of genetic diversity in cultivated sorghums using a core collection. Genome. 49 : 168-180.

Ekeke S (2012) Différenciation agro-morphologique entre le sorgho pluvial et le sorgho repiqué dans un itinéraire technique de sorgho repiqué. Mémoire d'Ingénieur, Institut Supérieur du Sahel, Université de Maroua, Cameroon.

Franks SJ, Sim S, Weis AE (2007) Rapid evolution of flowering time by an annual plant in response to a climate fluctuation. Proc Natl Acad Sci USA. 104: 1278-1282.

Fjellheim S, Boden S, Trevaskis B (2014) The role of seasonal flowering responses in adaptation of grasses to temperate climates. Front Plant Sci. 5:431.

Harlan JR., Pasquereau J (1969) Décrue agriculture in Mali. Econ Bot. 23: 70-74.

Izge AU, Alimta DP (2008) Comparative performance of Masakwa sorghum and other sorghum cultivars under rainfall conditions. Afr J Plant Sci Biotechnol. 2: 30-33.

Jaleel CA, Manivannan P, Lakshmanan GMA, Gomathinayagam M, Panneerselvam R (2008) Alterations in morphological parameters and photosynthetic pigment responses of Catharanthus roseus under soil water deficits. Colloid Surface B. 61: 298-303.

Jombart T, Devillard S, Balloux F (2010) Discriminant analysis of principal components: a new method for the analysis of genetically structured populations. BMC Genet. 11, 94 .

Kenga R, Djorowe G (2008) Variabilité morphologique des sorghos de saison sèche Muskwari du Nord Cameroun. Plant Genet Resour Newsletter. 153 : 9-14.

Le Roy X (2005) Le sorgho de décrue dans la vallée du Sénégal. In : Maollard E, Walter A (ed) Les agricultures singulières du monde. Paris, IRD, 8-13.

Levitt J (1972) Responses of plants to environmental stresses. Academic Press, New York.

Naoura G, Sawadogo N, Atchozou EA et al., (2019) Assessment of agro-morphological variability of dry-season sorghum cultivars in Chad as novel sources of drought tolerance. Sci Rep. 919581

Padilla FM, Pugnaire FI (2007) Rooting depth and soil moisture control Mediterranean woody seedling survival during drought. Funct Ecol. 21: 489-495.

Passioura JB (2012). Phenotyping for drought tolerance in grain crops: when is it useful to breeders? Funct Plant Biol. 39: 851-859.

Patil JV, Reddy PS, Prabhakar, Umakanth AV, Gomashe S, Ganapathy KN (2014). History of post-rainy season sorghum research in India and strategies for breaking the yield plateau. Ind J Genet Plant Breed. 74: 271-285.

R Core Team (2017) R: A language and environment for statistical computing. $R$ Foundation for Statistical Computing, Vienna, Austria. 
Raimond C (1999) Terres inondées et sorgho repiqué : évolution des espaces agricoles et pastoraux dans le bassin du lac Tchad. Université Paris 1, France.

Redmann R (1985) Adaptation of Grasses to Water Stress-Leaf Rolling and Stomate Distribution. Ann Mo Bot Gard. 72(4): 833-842.

Richards RA, Rebetzke GJ, Watt M, Condon AT, Spielmeyer W, Dolferus R (2010) Breeding for improved water productivity in temperate cereals: phenotyping, quantitative trait loci, markers and the selection environment. Funct Plant Biol. 37: 85-97.

Saïdou AA, Raimond C, Soler C, Cao Hamadou TV, Kenga R, Benoit L, Wencelius J, Fokou O, Chauvin C, Ekeke S, Joly HI (2014) Histoire d'une innovation agricole récente à l'échelle régionale : quelle différenciation des sorghos repiqués dans le bassin du lac Tchad ? Cah O M. 67: 141-168.

Sairam RK, Shukla DS, Saxena DC (1997) Stress induced injury and antioxidant enzymes in relation to drought tolerance in wheat genotypes. Biol Plantarum. 40: 357-364.

Sidibé Y, Williams TO, Kolavalli $S$ (2016) Flood recession agriculture for food security in Northern Ghana. GSSP Working Paper. Intl Food Policy Res Inst. DOI: 10.13140/RG.2.1.3250.8405
Soler C, Saïdou AA, Hamadou TVC, Pautasso M, Wencelius J, Joly HI (2013) Correspondence between genetic structure and farmers' taxonomy - a case study from dry-season sorghum landraces in northern Cameroon. Plant Genet Resour. 11: 36-49.

Soler C (2012) Dynamique de la diversité génétique du sorgho repiqué (Sorghum bicolor ssp. bicolor) au Nord-Cameroun : Facteurs biologiques et anthropiques. Montpellier : Thèse de doctorat, Université de Montpellier 2, $180 \mathrm{p}$.

Stemler ABL, Harlan JR, Dewet JMJ (1975) Caudatum sorghums and speakers of Chari-Nile languages in Africa. J Afr Hist. 16: 161:183.

Süß A, Danner M, Obster C, Locherer M, Hank T, Richter K (2015) Measuring Leaf Chlorophyll Content with the Konica Minolta SPAD-502Plus. Theory, Measurement, Problems, Interpretation. EnMAP Field Guides Technical Report, GFA Data Services.

Vitasse Y, Delzon S, Bresson CC, Michalet R, Kremer A (2009) Altitudinal differentiation in growth and phenology among populations of temperate-zone tree species growing in a common garden. Can J For Res. 39:1259-1269.

Zach B, Kirscht H, Löhr D, Neumann K, Platte E (1996) Masakwa dry season cropping in the Chad Basin. Berichte Des Sonderforschungsbereichs 268: 349-356. 